\title{
Effects of Vinegars on the Growth Performance of Black Tiger Post Larvae Shrimp, Penaeus monodon
}

\author{
Rey J. dela Calzada1, Barry Leonard M. Tumbokon², Augusto E. Serrano, Jr.,2* \\ ${ }^{1}$ Institute of Aquaculture, College of Fisheries and Ocean Sciences, University of the Philippines \\ Visayas, Miagao 5023 Iloilo, Philippines \\ ${ }^{2}$ National Institute of Molecular Biology and Biotechnology, University of the Philippines Visayas, \\ Miagao 5023 Iloilo, Philippines
}

Key words: acidifier, coconut-sap vinegar, sugar-cane vinegar, organic acids, growthperformance

\begin{abstract}
This study aimed to investigate the effect of acidifying the diet of black tiger shrimp Penaeus monodon on its growth and feed efficiency by supplementing coconut sap vinegar CSV) or sugar cane vinegar (SCV) or their 1:1 combination. Three hundred and sixty post larva shrimps (average initial weight of $0.01 \mathrm{~g}$ ) were randomly distributed into 12 50-L plastic containers. Four experimental diets, namely, control diet, 2\% CSV, $2 \%$ SCV and $2 \%$ CSV+SCV were fed to groups of shrimps. After 90 days, all shrimps fed with diets containing vinegar exhibited significantly higher final average body weight (FABW), weight gain (WG), feed intake, specific growth rate (SGR), and better feed conversion ratio (FCR) than those fed the control diet. Attractability tests showed that the CSV and CSV+SCV diets attracted significantly the highest percentage of shrimps after 10 min of feed placement. Survival rate was not significantly different among the treatments. In conclusion, the results demonstrated that the vinegars tested could be used as growth enhancers in shrimp and that the combination of coconut sap and sugar cane vinegars supplemented to the diet resulted in the best growth and feed efficiency as well as attracted the most percentage of shrimps.
\end{abstract}




\section{Introduction}

The rapid demand of shrimp in the global trade market has triggered intensification of production systems which led to increased stress, limited growth performance and poor welfare in farmed shrimp. Organic acids (OA) have gained much attention as feed additives to increase the nutritive value and growth of aquatic organism (Hoseinifar et al. 2016; $\mathrm{Ng} \& \mathrm{Koh}, 2017$ ). OAs and their salts contribute in nutritional ways as components in several metabolic pathways for energy generation, such as for ATP generation in the citric acid cycle or carboxylic acid cycle (Luckstad, 2008; da Silva et al. 2013). They also increase digestibility of dry matter, lipid, copper, zinc, calcium and phosphorous in fish (Lin and Cheng, 2017). OAs and their salts have the capacity to chelate minerals or improve the dephosphylation of phytic acid, leading to improved mineral digestion and absorption in fish (Baruah et al. 2007). They further increase the apparent digestibility of energy and phosphorus in white shrimp (da Silva et al. 2013). Feeding the Pacific white shrimp with diet supplemented with $2 \%$ butyrate increase feed efficiency, nitrogen retention, and protein efficiency (da Silva et al. 2016). Dietary inclusion of citric acid decreased the pH of gut digesta leading to significant increases in bone ash, $\mathrm{P}$ and Mn concentrations (Baruah et al. 2005).

Studies on the effects of OAs on the growth performance of shrimp, though limited, have shown positive results e.g. diet supplemented with butyrate and propionate improved the growth of Litopenaeus vannamei (da Silva et al. 2016). L. vannamei fed with a soybean meal-based diet supplemented with $2 \%$ dietary organic acid blends (OAB) significantly enhance the growth performance. (Romano et al. 2015). L. vannamei fed with diet supplemented with fumarate, succinate, butyrate and propionate had higher final weights (Silva et al. 2016). Penaeus monodon cultured in ponds fed with commercial diet supplemented with $2 \%$ organic acid blends (OAB) showed no significant effect on final growth compared to the control, although apparent digestibility of dry matter, crude protein, ash and phosphorus was significantly higher in shrimp fed $2 \%$ OAB. ( $\mathrm{Ng}$ et al. 2015). Vinegars, as source of organic acid, are found to enhance the growth of $L$. vannamei. Shrimps fed with apple cider, coconut sap and sugar cane vinegars at $2 \%$ inclusion, exhibited significantly higher final average body weight, weight gain and specific growth rate (Jamis et al. 2018).

The effects of supplementing common vinegars in the diet of the black tiger shrimp postlarvae have not been studied so far. The present study investigated the effects of two native vinegars, namely coconut sap vinegar and sugar cane vinegar and their combination on the growth performance of Penaeus monodon post larvae.

\section{Materials and Methods}

The experiments were conducted at the laboratory of the National Institute of Molecular Biology and Biotechnology (NIMBB), University of the Philippines Visayas, Miagao, Iloilo, Philippines.

Experiment shrimps and design

Healthy and specific pathogen free $P$. monodon post-larvae were obtained from a local commercial shrimp hatchery in Guimbal, Iloilo. The post-larvae were acclimatized to laboratory conditions and feed with commercial $P$. monodon diet at $15 \%$ body weight day ${ }^{-1}$ for one week.

Feeding Trial

A total of 360 healthy post-larval Penaeus monodon (average body weight $=0.01 \mathrm{~g}$ ), were divided into twelve 50L-plastic containers (i.e. three replicates per dietary treatment) and fed with the experimental diets (Table 1) for 12 weeks. Diet 1 served as control (no vinegar) while diets 2,3 and 4 contained $2 \%(\mathrm{w} / \mathrm{w})$ coconut sap vinegar (CSV), sugar cane vinegar (SCV) and the combination of the two vinegars at $1: 1$ ratio (CSV+SCV). The feeding trial was done at salinity of 20 parts per thousand, \%o) in a closed water recirculating system at 30 shrimps tank ${ }^{-1}$. Each experimental diet was randomly assigned to each plastic container which was considered as the experimental unit. Experimental diets were given four times a day at $0800 \mathrm{H}, 1100 \mathrm{H}, 1400 \mathrm{H}$ and $1700 \mathrm{H}$ at the initial feeding rate of $15 \%$ of shrimp biomass for the first week, adjusted daily depending on the presence or absence of residual feed (Silva et al. 2016). Uneaten feed, faecal waste, moulted exuviae and dead shrimp were siphoned daily. All experimental aquaria was provided with aeration and uniform flow of water (30L/h/container). Periodic sampling by bulk weighing was done during the first day of stocking and every 15 days thereafter until termination of the experiment. 
Feed and diet preparation

Experimental feeds ( $43 \%$ crude protein, basal diet) were prepared from the basal diet (Table 1). Vinegars (or water for the controld diet) were sprayed on the basal diet at $2 \%$ concentration. The experimental diets were air dried at room temperature overnight.

Table 1 Ingredient ( $\mathrm{g} \mathrm{kg}^{-1}$ dry matter) and proximate composition of diet.

\begin{tabular}{|c|c|c|c|c|}
\hline \multirow[b]{3}{*}{ Ingredient } & \multicolumn{4}{|c|}{ Treatment (\% Composition) } \\
\hline & Diet 1 & Diet 2 & Diet 3 & Diet 4 \\
\hline & (no vinegar) & $(\mathrm{CSV})$ & $(\mathrm{SCV})$ & $(1: 1, \mathrm{CSV}: S C V)$ \\
\hline Peruvian fishmeal & 230.00 & 230.00 & 230.00 & 230.00 \\
\hline Acetes meal & 300.00 & 300.00 & 300.00 & 300.00 \\
\hline Soybean meal & 200.00 & 200.00 & 200.00 & 200.00 \\
\hline Cornstarch & 130.00 & 130.00 & 130.00 & 130.00 \\
\hline Cod liver oil & 60.00 & 60.00 & 60.00 & 60.00 \\
\hline CMC & 54.80 & 54.80 & 54.80 & 54.80 \\
\hline Lecithin & 5.00 & 5.00 & 5.00 & 5.00 \\
\hline Trace mineral mix & 10.00 & 10.00 & 10.00 & 10.00 \\
\hline Vitamin premix & 10.00 & 10.00 & 10.00 & 10.00 \\
\hline BHT & 0.20 & 0.20 & 0.20 & 0.20 \\
\hline Total & 1000.00 & 1000.00 & 1000.00 & 1000.00 \\
\hline \multicolumn{5}{|c|}{ Proximate composition of the basal diet ( $\mathrm{g} \mathrm{kg}^{-1} \mathrm{dry}$ weight ) } \\
\hline Dry matter & 918.50 & & & \\
\hline Crude protein & 436.50 & & & \\
\hline Crude fat & 83.10 & & & \\
\hline Crude fiber & 22.80 & & & \\
\hline Crude ash & 130.50 & & & \\
\hline Nitrogen Free Extract & 245.60 & & & \\
\hline Gross Energy (kcal kg-1) & 3476.30 & & & \\
\hline
\end{tabular}

$\mathrm{CSV}=$ coconut sap vinegar; $\mathrm{SCV}=$ sugarcane vinegar

Feed attractability test

Six test runs were conducted using rectangular glass tanks with multiple chambers (Suresh et al. 2011). Each tank consisted of 3 major chambers (acclimatization chamber, middle chamber, and feeding chamber). The three chambers were separated by sliding glass shutters and could be lifted when necessary. The feeding chamber consisted of 5 sub-chambers, each with a $6 \times 5 \mathrm{~cm}$ opening through which the shrimps could have access to the feeding chamber. Each attractability tank was filled with $40 \mathrm{~L}$ seawater (20 parts per thousand, \%o) and was set up in a laboratory with artificial lighting.

Ten shrimps $(A B W=0.56 \pm 0.02 \mathrm{~g})$, randomly selected, were stocked in the acclimatization chamber and acclimatized for $1 \mathrm{~h}$. Two (2) $\mathrm{g}$ of each test diet was placed in each of the chambers randomly. The shutter was removed 2 min after feed placement to allow the shrimps to have access to the experimental feeds. Feed preference was quantified by counting the number of shrimps in the feeding chambers at 1, 5, and 10 min following lifting of the shutter. Total percentage of shrimp within the feeding chamber at any particular time was calculated. 


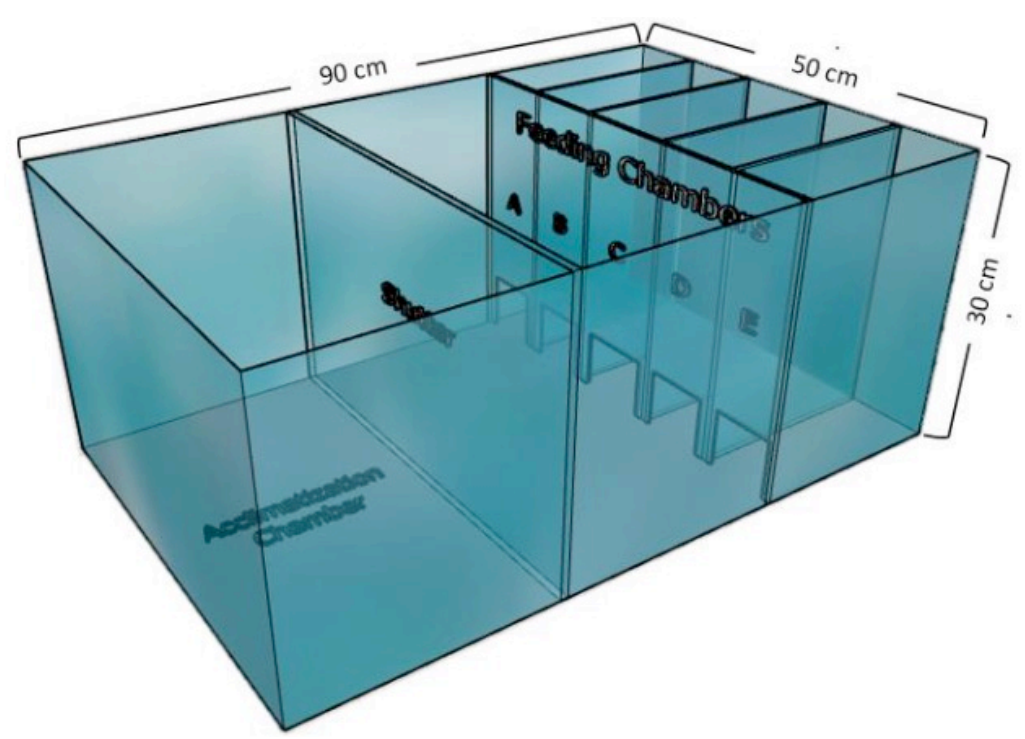

Figure 1 Schematic diagram of the tank used for the attractability test.

Biometry and growth parameters

At the conclusion of the trial (90 days), weight gain (WG), specific growth rate (SGR), protein efficiency ratio (PER), feed intake (FI), feed conversion ratio (FCR) and survival rate (SURV), were estimated using the following formulas:

Weight gain $(\mathrm{g})=$ Final weight-Initial weight

SGR $\left(\%\right.$ day $\left.^{-1}\right)=100 *[($ In final weight $(\mathrm{g})-$ In initial weight $(\mathrm{g})) /$ Experimental period $]$

PER $=$ total wet weight gain $(\mathrm{g}) /$ crude protein fed $(\mathrm{g})$

$\mathrm{FCR}=$ Total feed intake $(\mathrm{g}) /$ Total wet weight gain $(\mathrm{g})$

Survival Rate $(\%)=($ Total number of shrimp survived/ Total number of shrimp stocked $) * 100$

\section{Statistical Analyses}

SPSS version 16 software was used to perform statistical analysis. Shapiro-Wilk test was used to test for normality and Levene's test for variance in homogeneity. Once the data passed these two tests, One-way analysis of variance (ANOVA) was done at $a=0.05$, followed by Post hoc analyses using Duncan's Multiple Range Test (DMRT) to identify differences between independent factors, if the results of ANOVA indicate significant difference. The percentage number of shrimp from attractability test as well as the survival rates was arcsin-transformed before subjecting to ANOVA.

\section{Results}

At the termination of the feeding trial, final average body weight (FABW) was significantly higher in shrimp fed diets containing vinegars than that with the control diet (Figure 1). 


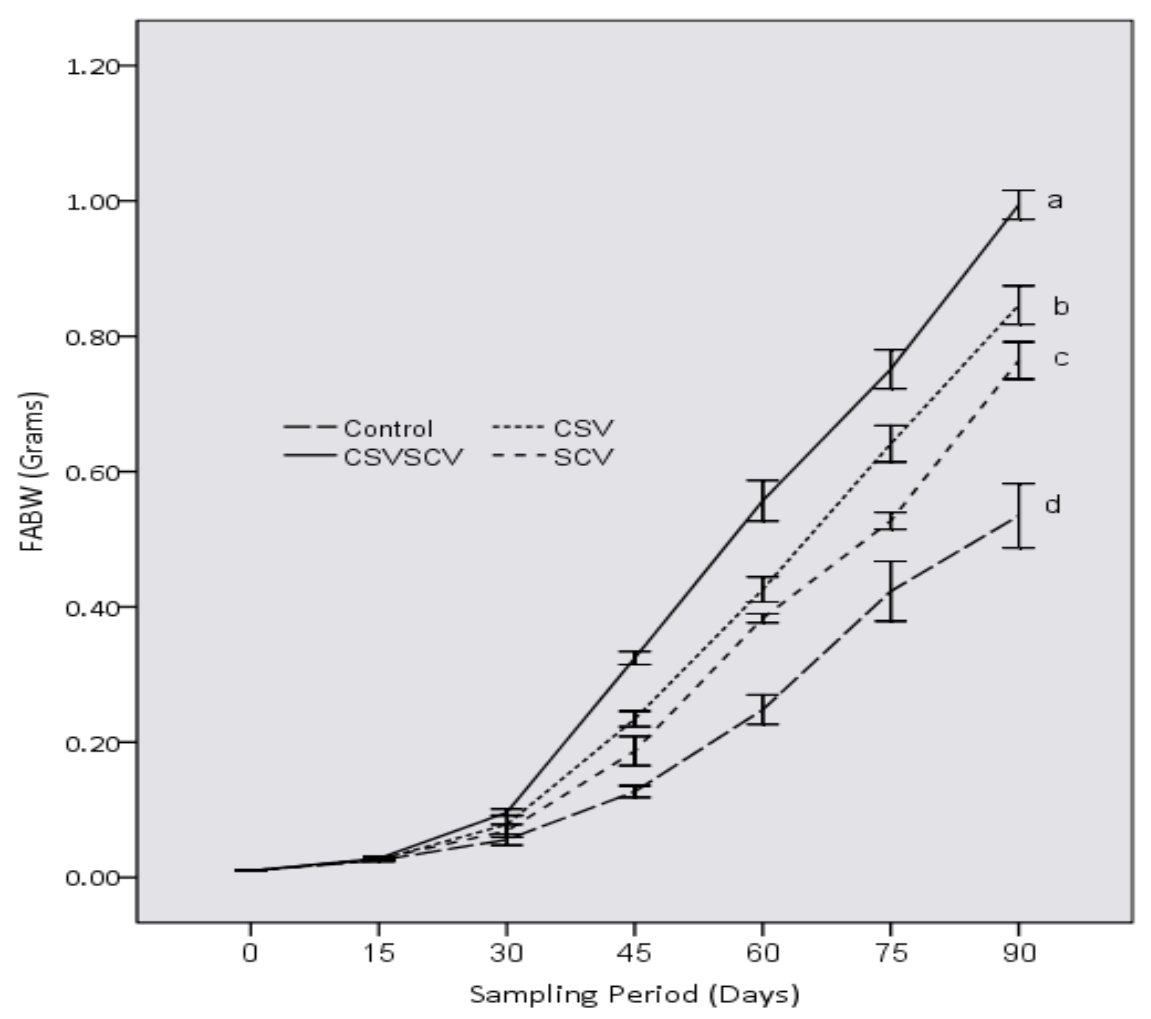

Figure 2 Periodic final average body (FABW) weight of shrimp fed the control diet and diets containing coconut sap vinegar (CSV), sugar cane vinegar (SCV) and combination of coconut sap vinegar and sugar cane vinegar (CSVSCV).

FABW, WG, FI, SGR, PER and FCR were significantly higher in all vinegar groups than those in the control group $(p<0.05)$ (Table 2 ). The CSV+SCV diet exhibited significantly the highest FABW, WG, SGR, PER and the best FCR (i.e. the lowest value) among all treatments. FI of shrimps fed the CSV and SCV group were statistically similar but significantly lower than those in the CSV+SCV group. Survival rate at the termination of the experiment were all equally high in all dietary treatments and were not significantly different from each other (Table 2).

Table 2 Growth performance and feed utilization of $P$. monodon fed with control and vinegars in 90 days.

\begin{tabular}{lcccccccc}
\hline Treatment & I ABW $(\mathrm{g})$ & $\mathrm{F}_{\mathrm{ABW}}(\mathrm{g})$ & WG $(\mathrm{g})$ & $\mathrm{FI}(\mathrm{g})$ & $\begin{array}{c}\text { SGR } \\
(\% / \text { day })\end{array}$ & PER & FCR & SURV $(\%)$ \\
\hline Control & 0.01 & $0.53 \pm 0.02^{\mathrm{d}}$ & $0.52 \pm 0.02^{\mathrm{d}}$ & $1.11 \pm 0.04^{\mathrm{c}}$ & $4.41 \pm 0.05^{\mathrm{d}}$ & $1.20 \pm 0.06^{\mathrm{d}}$ & $2.08 \pm 0.03^{\mathrm{a}}$ & $84.44 \pm 1.11^{\mathrm{a}}$ \\
CSV & 0.01 & $0.85 \pm 0.01^{\mathrm{b}}$ & $0.84 \pm 0.01^{\mathrm{b}}$ & $1.50 \pm 0.04^{\mathrm{ab}}$ & $4.92 \pm 0.02^{\mathrm{b}}$ & $1.91 \pm 0.03^{\mathrm{b}}$ & $1.77 \pm 0.02^{\mathrm{c}}$ & $84.44 \pm 1.11^{\mathrm{a}}$ \\
SCV & 0.01 & $0.75 \pm 0.00^{\mathrm{c}}$ & $0.74 \pm 0.00^{\mathrm{c}}$ & $1.47 \pm 0.02^{\mathrm{b}}$ & $4.80 \pm 0.01^{\mathrm{c}}$ & $1.70 \pm 0.03^{\mathrm{c}}$ & $1.95 \pm 0.04^{\mathrm{b}}$ & $84.44 \pm 1.11^{\mathrm{a}}$ \\
CSV+SCV & 0.01 & $0.99 \pm 0.02^{\mathrm{a}}$ & $0.98 \pm 0.01^{\mathrm{a}}$ & $1.64 \pm 0.02^{\mathrm{a}}$ & $5.10 \pm 0.01^{\mathrm{a}}$ & $2.25 \pm 0.02^{\mathrm{a}}$ & $1.65 \pm 0.01^{\mathrm{d}}$ & $84.44 \underline{1.1 .11^{\mathrm{a}}}$
\end{tabular}

Means \pm SE indicated. Means within columns with the same superscripts are not significantly different $(P>0.05)$.

IABW=initial average body weight; FABW=final average body weight; WG=weight gain; TIFI=total individual feed intake; $\mathrm{SGR}=$ specific growth rate; $\mathrm{PER}=$ protein efficiency ratio; $\mathrm{FCR}=$ food conversion ratio; SURV=survival rate; $C S V=$ coconut sap vinegar; $\mathrm{SCV}=$ sugar cane vinegar.

During the attractability tests (Table 3), shrimps entered and transferred to the different feeding chambers from the start ( 1 min after placement) to the end (10 min); thus, the proportion of the shrimps at each feeding chamber changed at $1 \mathrm{~min}, 5 \mathrm{~min}$ and $10 \mathrm{~min}$ after feed placement. When this percentages are averaged, results showed that the CSV and CSV+SCV diets, which were not statistically different, significantly attracted higher proportion of shrimps than did the SCV and the control diets, and were also not significantly different from each other. 
Table 3 Attractability of $P$. monodon to the experimental diets.

\begin{tabular}{lcccc}
\hline \multicolumn{4}{c}{ Number of shrimp (\%) } \\
\hline \multicolumn{1}{c}{ Diet } & $1 \mathrm{~min}$ & $5 \mathrm{~min}$ & $10 \mathrm{~min}$ & Total \\
Control & $1.7 \pm 1.7^{\mathrm{a}}$ & $6.7 \pm 2.1^{\mathrm{a}}$ & $0.0^{\mathrm{a}}$ & $8.3 \pm 1.7^{\mathrm{a}}$ \\
CSV & $11.7 \pm 4.0^{\mathrm{ab}}$ & $18.3 \pm 4.0^{\mathrm{b}}$ & $6.7 \pm 3.3^{\mathrm{ab}}$ & $33.4 \pm 6.7^{\mathrm{b}}$ \\
SCV & $1.67 \pm 1.7^{\mathrm{a}}$ & $8.3 \pm 3.7^{\mathrm{ab}}$ & $0.0^{\mathrm{a}}$ & $11.7 \pm 1.7^{\mathrm{a}}$ \\
CSV+SCV & $16.7 \pm 5.6^{\mathrm{b}}$ & $18.3 \pm 4.0^{\mathrm{b}}$ & $11.7 \pm 4.0^{\mathrm{b}}$ & $46.7 \pm 6.7^{\mathrm{b}}$ \\
\hline
\end{tabular}

Means in the same column with different superscripts indicate differences between diets $(p<0.05)$. CSV= Coconut Sap Vinegar diet; SCV=Sugar cane vinegar; CSV+SCV= Combination of CSV and SCV.

\section{Discussion}

Several studies have reported the beneficial effects of organic acids on the growth of shrimp. Results in the present study agree with those of Penaeus vannamei in which feeding diets containing $2 \%$ vinegars (Jamis et al. 2018) results in higher FABW, WG, and SGR. In the Pacific white shrimp, feeding a soybean meal-based diet containing $2.0 \mathrm{~g} \mathrm{~kg}^{-1}$ dietary organic acid blends (OAB) enhances growth performance (Romano et al. 2015) while the diet containing $2.0 \mathrm{~g} \mathrm{~kg}^{-1}$ dietary citric acid increases WG by $15.9 \%$ and decreases FCR by 0.17 (Su et al. 2014). Sodium butyrate and sodium propionate at $0.5 \%, 1 \%$ and $2 \%$ inclusion increase the FABW but only the diet containing $2 \%$ sodium butyrate improves feed efficiency, nitrogen retention, protein efficiency rate, survival and yield of shrimps in comparison with those of the control group of Litopenaeus vannamei. (Silva et al. 2016). In contrast, L. vannamei fed diets containing apple cider vinegar did not affect the growth after 60 days of feeding (Pourmozaffar et al. 2016). Some of the contributing factors believed to improve the growth of fish fed OA-supplemented diets include improved nutrient digestion and mineral utilization, acidifying effects to the diets, stomach and gut as well as a reduction of gastrointestinal bacteria-colony-forming unit (CFU) and/or altered bacterial composition ( $\mathrm{Ng}$ et al. 2015, Sugiura et al. 2006, Su et al. 2014). OA (1) improves protein, dry matter, and/or P (phosphorus) digestibility in L. vannamei (da Silva et al. 2013) (2) contributes intermediate substrates for several metabolic pathways for energy generation (e.g. ATP generation in the citric acid cycle or carboxylic-acids cycle; da Silva et al. 2013) and (3) enhances enzyme activities in shrimp and fish (Silva et al. 2016; Su et al. 2014; Li et al. 2009; Castillo et al. 2014).

Food detection in shrimps is highly dependent on chemical cues. The attractability of diets supplemented with CSV+SCV could be attributed to the properties of each of the vinegar. Results of the attractability in the present study on Penaeus monodon agree well with those in Litopenaeus vannamei in which the diet containing CSV attracted the most number of the Pacific white shrimps (Jamis et al. 2018). In our laboratory, we have subjected the two vinegars to the volatile compound analysis using Gas Chromatography, and results showed that very few volatile compounds were detected in SCV (unpublished data) while a number of these were detected in CSV. Among the volatile compounds detected in CSV which were prominent included 2,3 butanediol, 1,3propanediol, and 4-hydroxy 2-butanone among others. Chen et al (2017) have reported 23 aroma compounds. These investigators mentioned that 2,3-butanediol is an aroma which correlated with the preference data on palatability of dog food to beagles. Also, 4-hydroxy 2-butanone is a fruit flies attractant. 1,3-Propanediol is used in livestock for other reasons like ketosis prevention which are not related to feed attractability. These aroma compounds detected in the CSV could have attributed the significantly higher proportion of shrimps attracted to the diet which contained CSV alone or in CSV+SCV. Most aquatic chemical signals identified so far among aquatic animals are soluble molecules relatively small, where amino acids predominate (Nunes et al. 2006). CSV is reported to contain amino acids, volatile acid, phenolic compounds and vitamin C (Xia et al. 2011)). The acetic acid content in vinegars gives the strong aroma and unique flavour and act as precursor for the formation of other volatile compounds such as aldehydes, esters, ketones, and organic acids and contribute to the organoleptic properties of vinegars (Ozturk et al. 2015). In shrimp, arousal to feeding minimizes leaching of feed nutrients caused by the animal's slow feeding behavior (Peñaflorida \& Virtanen, 1996) by enabling them to feed on the diet before leaching could occur. It has been reported that the quantities of leaching observed to be high in acetate, exhibiting $100 \%$ in 30 min (da Silva et al. 2013). The attractability of diet stimulates shrimp to initiate feeding and continue feeding (Lee and Meyers, 1996; Nunes et al. 2006; Derby et al. 2016) and ultimately leads to enhanced growth performance (Smith et al. 2005; Suresh et al. 2011). 
To the best of our knowledge, this study is the first to report the beneficial effect of vinegars on the growth of $P$. monodon. In conclusion, feeding Penaeus monodon post larvae with diets supplemented with the vinegars improved growth performance and feed utilization. The combination diet (CSV+SCV) exhibited the highest FABW, WG, FI, SGR and lowest FCR. Also, the diet containing CSV alone or $1: 1 \mathrm{CSV}+\mathrm{SCV}$ were very effective in attracting the most proportion of shrimps among other dietary treatments.

\section{Acknowledgements}

The authors would like to thank the Philippine Council for Agriculture, Aquatic and Natural Resources Research and Development (PCAARRD) of the Department of Science and Technology for the research grant; the Office of the Vice-Chancellor of Research and Extension for the publication grant and the Philippine Council for Agriculture, Aquatic and Natural Resources Research and Development (PCAARRD) of the Department of Science and Technology for the scholarship of Mr. Rey J. dela Calzada.

\section{References}

Baruah K., Pal A. K., Sahu N. P., Jain K. K., Mukherjee S. C. and D. Debnath, 2005. Dietary protein level, microbial phytase, citric acid and their interactions on bone mineralization of Labeo rohita (Hamilton) juveniles. Aquac Res, 36(8), 803-812.

Baruah K., Sahu N. P., Pal A. K., Jain K. K., Debnath D. and S.C. Mukherjee, 2007. Dietary microbial phytase and citric acid synergistically enhances nutrient digestibility and growth performance of Labeo rohita (Hamilton) juveniles at sub-optimal protein level. Aquac Res, 38(2), 109-120.

Castillo S., Rosales M., Pohlenz C., and D.M. Gatlin III, 2014. Effects of organic acids on growth performance and digestive enzyme activities of juvenile red drum Sciaenops ocellatus. Aquaculture, 433, 6-12.

Chen M., Chen X., Nsor-Atindana J., Masamba K. G., Ma J. and F. Zhong, 2017. Optimization of key aroma compounds for dog food attractant. Anim Feed Sci and Tech, 225, 173-181.

da Silva B.C., Vieira F.D.N., Mouriño J.L.P., Bolivar N. and W.Q. Seiffert, 2016. Butyrate and propionate improve the growth performance of Litopenaeus vannamei. Aquac Res, 47(2), 612-623. da Silva B.C., do Nascimento Vieira F., Mourino J.L.P., Ferreira G.S. and W.Q. Seiffert, 2013. Salts of organic acids selection by multiple characteristics for marine shrimp nutrition. Aquaculture 384: 104-110.

Derby C.D., Elsayed F.H., Williams S.A., González C., Choe M., Bharadwaj A. S. and G.W. Chamberlain, 2016. Krill meal enhances performance of feed pellets through concentrationdependent prolongation of consumption by Pacific white shrimp, Litopenaeus vannamei. Aquaculture, 458, 13-20.

Hoseinifar S. H., Sun Y. and C.M. Caipang, 2016. Short-chain fatty acids as feed supplements for sustainable aquaculture: An updated view. Aquac Res, 48(4), 1380-1391.

Jamis J.O., Tumbokon B.L.M., Caigoy J.C.C., Bunda, M.G.B. and A.E Serrano Jr., 2018. Effects of vinegars and sodium acetate on the growth performance of Pacific white shrimp, Litopenaeus vannamei. Isr J Aquacult-Bamid, 70:1506.

Lee P.G. and S.P. Meyers, 1996. Chemoattraction and feeding stimulation in crustaceans. Aquacult Nutri, 2(3), 157-164.

Li J.S., Li J.L. and T.T. Wu, 2009. Effects of non-starch polysaccharides enzyme, phytase and citric acid on activities of endogenous digestive enzymes of tilapia (Oreochromis niloticus $\mathrm{x}$ Oreochromis aureus). Aquacult Nutri, 15: 415-420.

Lin Y.H. and M.Y. Cheng, 2017. Effects of dietary organic acid supplementation on the growth, nutrient digestibility and intestinal histology of the giant grouper Epinephelus lanceolatus fed a diet with soybean meal. Aquaculture, 469, 106-111.

Luckstadt C., 2008. The use of acidifiers in fish nutrition. Perspectives in Agriculture, Veterinary Science, Nutrition and Natural Resources, 3(044), 1-8.

Ng, W. K. and C.B. Koh, 2017. The utilization and mode of action of organic acids in the feeds of cultured aquatic animals. Rev Aquacult, 9(4), 342-368.

Ng W.K., Koh C.B., Teoh C.Y. and N. Romano, 2015. Farm-raised tiger shrimp, Penaeus monodon, fed commercial feeds with added organic acids showed enhanced nutrient utilization, immune response and resistance to Vibrio harveyi challenge. Aquaculture, 449, 69-77. 
Nunes A.J., Sá, M.V., Andriola-Neto F.F. and D. Lemos, 2006. Behavioral response to selected feed attractants and stimulants in Pacific white shrimp, Litopenaeus vannamei. Aquaculture, 260 (1-4), 244-254.

Ozturk I., Caliskan O., Tornuk F., Ozcan N., Yalcin H., Baslar M. and O. Sagdic, 2015. Antioxidant, antimicrobial, mineral, volatile, physicochemical and microbiological characteristics of traditional home-made Turkish vinegars. Lebenson Wiss Technol, 63(1), 144-151.

Peñaflorida V.D. and E. Virtanen, 1996. Growth, survival and feed conversion of juvenile shrimp (Penaeus monodon) fed a betaine/amino acid additive. Isr J Aquacult-Bamid, 48(1), 3-9.

Pourmouzafar S., Hajimardloo A. and H.K. Mindare, 2017. Dietary efect of apple cider vinegar and propionic acid on immune related transcriptional response and growth performance in white shrimp. Litopenaeus vannamei. Fish Shellfsh Immunol, 60, 60-71.

Romano N., Koh C. and W. Ng, 2015. Dietary microencapsulated organic acids blend enhances growth, phosphorus utilization, immune response, hepatopancreatic integrity and resistance against Vibrio harveyi in white shrimp, Litopenaeus vannamei. Aquaculture, 435,228-236.

Silva B.C., Nolasco-Soria H., Magallón-Barajas F., Civera-Cerecedo R., Casillas-Hernández R. and W. Seiffert, 2016. Improved digestion and initial performance of whiteleg shrimp using organic salt supplements. Aquacult Nutri, 22(5), 997-1005.

Smith D.M., Tabrett S.J., Barclay M.C. and S.J. Irvin, 2005. The efficacy of ingredients included in shrimp feeds to stimulate intake. Aquacult Nutri, 11(4), 263-272.

Su X., Li X., Leng X., Tan C., Liu B., Chai X. and T. Guo, 2014. The improvement of growth, digestive enzyme activity and disease resistance of white shrimp by the dietary citric acid. Aquacult Int, 22:1823-1835.

Sugiura S.H., Roy P.K. and R.P. Ferraris, 2006. Dietary acidification enhances phosphorus digestibility but decreases H+/K+-ATPase expression in rainbow trout. J Exp Biol, 209 (19), 37193728.

Suresh A. V., and S. Nates, 2011. Attractability and palatability of protein ingredients of aquatic and terrestrial animal origin, and their practical value for blue shrimp, Litopenaeus stylirostris fed diets formulated with high levels of poultry byproduct meal. Aquaculture, 319(1-2), 132-140.

Xia Q., Li R., Zhao S., Chen W., Chen H., Xin B.... and M. Tang, 2011. Chemical composition changes of post-harvest coconut inflorescence sap during natural fermentation. Afr $J$ Biotechnol, 10(66), 14999-15005. 